\title{
Virilizing Adrenal Carcinoma in Two Sibs
}

\section{MOHSEN MAHLOUDJI, HOSSAIN RONAGHY, and WERNER DUTZ}

\author{
From the Departments of Neurology, Medicine, and Pathology, Pahlavi University Medical School, Shiraz, Iran
}

Though the familial occurrence of virilization associated with hyperplasia of the adrenal cortex has long been established, there have been only two reports of the familial aggregation of virilizing adrenal carcinoma. It is the purpose of the present communication to describe a family in which 2 sibs, who were products of a consanguineous marriage, had virilizing tumours of the adrenal cortex proved histologically.

\section{Case Reports}

Case 1. A 14-year-old girl was admitted into hospital in May 1968 with the chief complaint of excessive hair growth for 9 years. She was born at home after a full-term pregnancy and normal delivery and was apparently well until the age of 5 years. At that time hair on face, body, and genitalia was noticed, with acne of face, chest, and back. Hair growth was enough to necessitate shaving at regular intervals. Change of voice occurred soon thereafter. She had never menstruated. Four months before admission she had headache, blurring of vision, dizziness, and some pain over the lower abdomen and right flank. She received various drugs without benefit.

Physical examination. The weight of the patient was $42 \mathrm{~kg}$, height $134 \mathrm{~cm}$, and blood pressure $190 / 140 \mathrm{~mm}$ $\mathrm{Hg}$. She was short in stature, muscular, with a round flushed face, and had acne and generalized hirsutism (Fig. 1). Scalp hair was scanty and of male distribution. The voice was husky. The thyroid gland was not palpable. Breasts were infantile. The clitoris was enlarged (Fig. 2). The urethral opening was normal, the vagina small and narrow, barely admitting the tip of a small finger. The uterus and ovaries could not be palpated rectally. A hard immobile mass of about 10 $\mathrm{cm}$ in diameter was palpated over the right flank. All other findings were within normal limits.

Investigation revealed a haemoglobin of $16 \mathrm{~g} / 100 \mathrm{ml}$ haematocrit $47 \%$, and erythrocyte sedimentation rate corrected to $44 \mathrm{~mm}$ in the 1st hour. Fasting blood sugar was $80 \mathrm{mg} / 100 \mathrm{ml}$, potassium $3 \cdot 2$, chloride 98 , and sodium $138 \mathrm{mEq} / \mathrm{l}$. Phosphorus was $3.9 \mathrm{mg} / 100 \mathrm{ml}$, calcium $10.5 \mathrm{mg} / 100 \mathrm{ml}$, and alkaline phosphatase 49

Received 16 June 1970.
Shinowara units. Urine calcium was $238 \mathrm{mg} / 100 \mathrm{ml}$ in 24 hours. Vanillyl mandelic acid excretion was normal. Karyotype was that of a normal female. Basal values for ketosteroids and the results of dexamethazone suppression tests are summarized in the Table.

Radiographs of the chest showed multiple nodular lesions consistent with metastases. Air insufflation and intravenous pyelogram revealed displacement of the right kidney by a large mass. Skull $x$-ray showed generalized mild hyperostosis. The bone age was 18 years.

She had several episodes of high fever in hospital and deteriorated rapidly. Steroids in high dosage and antibiotic therapy were of no benefit. She went into respiratory failure and died 6 weeks after admission.

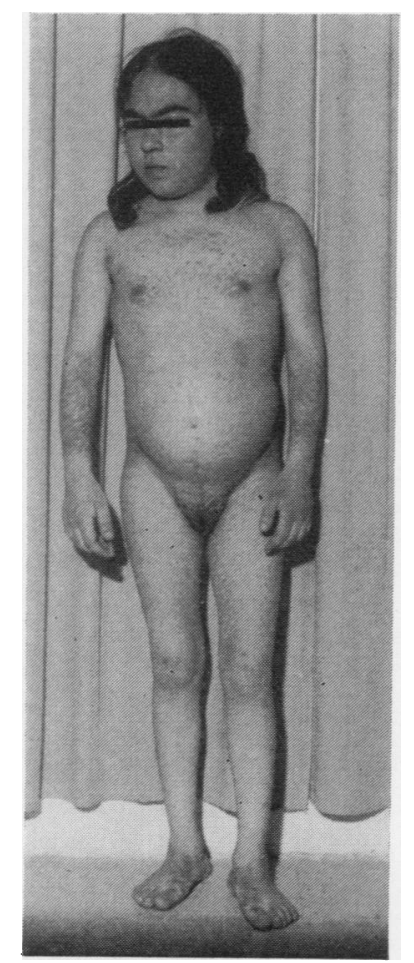

FIG. 1. Appearance of Case 1 at 14 years. 


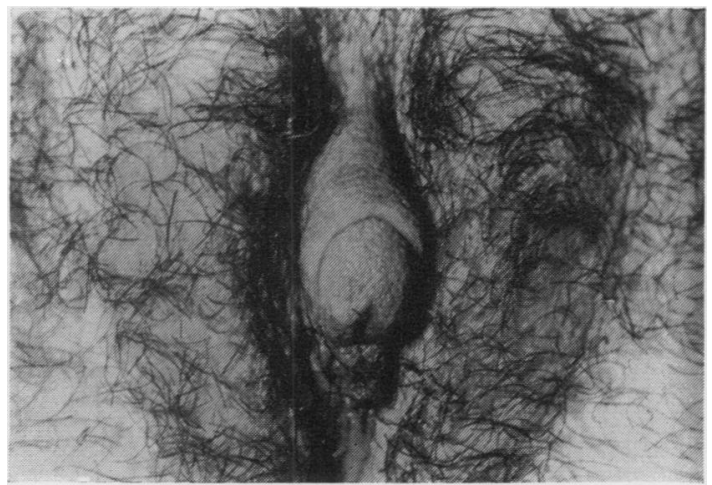

Fig. 2. External genitalia of Case 1.

TABLE

VALUES FOR KETOSTEROIDS AND DEXAMETHAZONE SUPPRESSION TEST

\begin{tabular}{|c|c|c|c|}
\hline Day & Drugs Given & $\begin{array}{c}\text { 17-Ketosteroids } \\
(\mathbf{m g} / 24 \mathrm{hr})\end{array}$ & $\begin{array}{c}\text { 17-Ketogenic } \\
\text { Steroids } \\
\text { (mg/24 hr) }\end{array}$ \\
\hline $\begin{array}{l}1 \\
2 \\
4\end{array}$ & $0.5 \mathrm{mg}$ - & $\begin{array}{l}70 \\
75\end{array}$ & $\begin{array}{l}75 \\
80\end{array}$ \\
\hline $\begin{array}{r}5 \\
6 \\
11\end{array}$ & 2 mg - & $\begin{array}{l}90 \\
95 \cdot 5\end{array}$ & $\begin{array}{l}96 \\
98\end{array}$ \\
\hline $\begin{array}{l}12 \\
13 \\
14 \\
15 \\
16 \\
17\end{array}$ & $\begin{array}{l}\text { 二 } \\
\text { = }\end{array}$ & $\begin{array}{l}112.5 \\
117 \cdot 5 \\
125 \\
119 \\
96 \\
109\end{array}$ & $\begin{array}{l}\overline{119} \cdot 4 \\
\bar{z} \\
103 \cdot 6\end{array}$ \\
\hline
\end{tabular}

Necropsy Findings. Necropsy was limited to abdominal exploration. The body was opened through a right costolumbar incision. A large well-encapsulated mass measuring $25 \mathrm{~cm}$ in diameter was removed piecemeal. The centre was necrotic with many recent haemorrhages. The capsule showed focal calcifications. The tumour revealed a bright yellow rim of viable tissue. The kidneys were compressed and pushed downwards. Exploration of the abdominal cavity revealed hepatic metastases. The internal genitalia were abnormally small. The left retroperitoneal area and the left adrenal region were free of tumour.

Histological examination revealed that large areas of the neoplasm were necrotic. The viable regions showed a very pleomorphic tumour with numerous symplastic giant cells (Fig. 3), marked nuclear clumping, and chromatin dispersion. There were 3-4 mitoses per high power field. Extensive capsular infiltration was present. Veins contained numerous clumps of tumour cells. Capillaries were filled with tumour clusters (Figs. 4 and 5). The pattern was typical of an adrenal cortical carcinoma.

3-J.M.G.

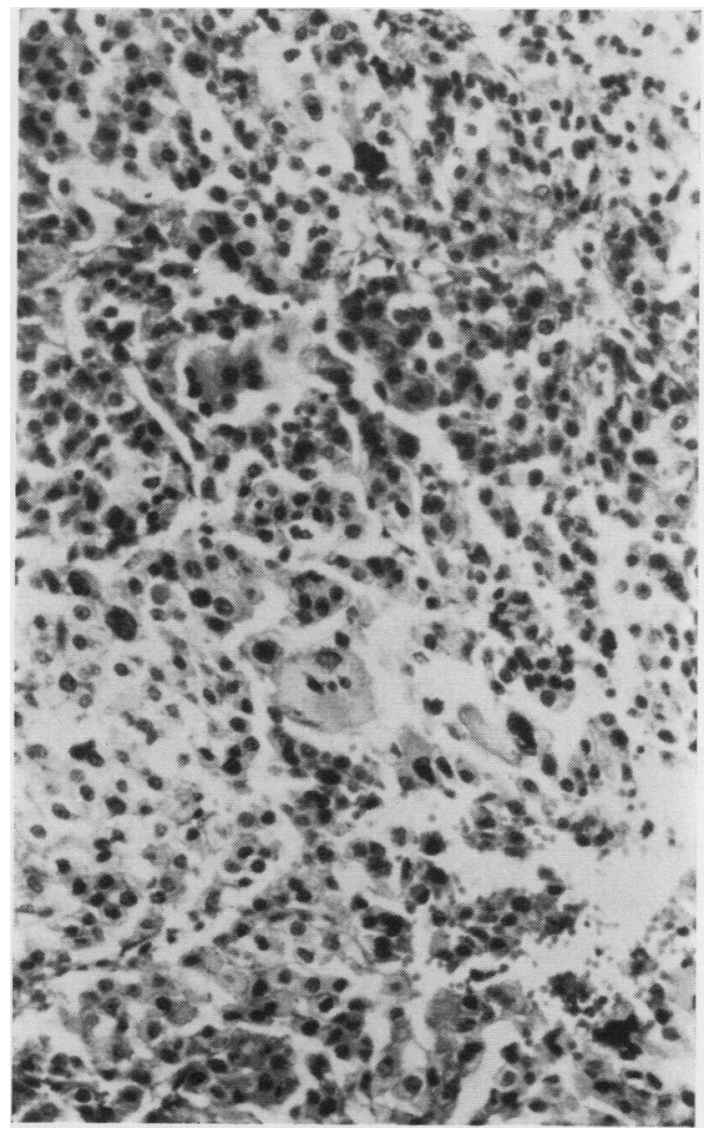

FIg. 3. Adrenal cortex of Case 1 showing adrenal cortical carcinoma with marked cellular anaplasia. (H. and E. $\times 100$.)

Case 2. An older brother of Case 1 who had died 15 years previously. He had developed normally until the age of 4 years when he began to grow a moustache and pubic hair. He was taken to a local hospital where an abdominal mass was discovered. He had a laparotomy but died 2 hours after operation. The histological reexamination of the tumour revealed a lesion indistinguishable from the tumour in Case 1, with all the characteristic features of adrenal carcinoma as described above.

\section{Clinical Comments}

Case 1 showed intense virilism manifested by voice change, hirsutism with frontal balding, acne, polycythaemia, failure of breast development, and primary amenorrhoea. The short stature, precocious bone age, failure of breast development, and absence of menses substantiated the history of onset of the disorder in childhood. However, the absence of any genital malformation and the clinical manifestations of glucocorticoid and mineralocorticoid excess (round red face, 


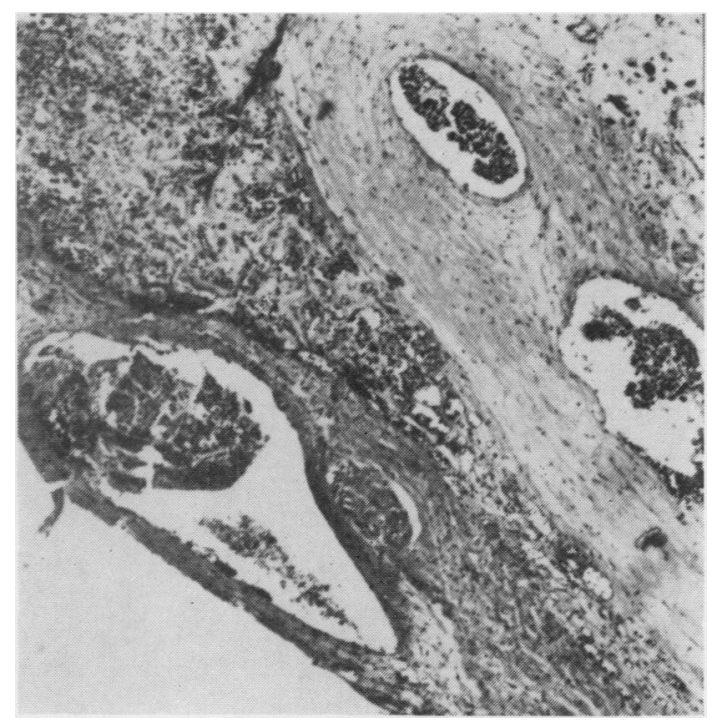

Fig. 4. Adrenal cortex of Case 1 showing tumour invasion of cortical veins. (H. and E. $\times 3$.)

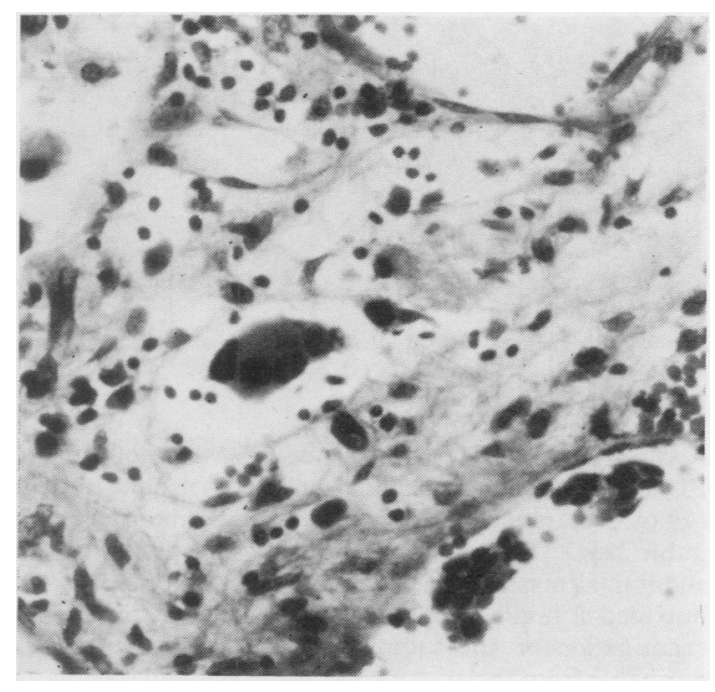

Fig. 5. Adrenal cortex of Case 1 showing tumour giant cell in cortical capillary. (H. and E. $\times 350$.)

obesity, glycosuria without fasting, hyperglycaemia, persistent hypertension) were not characteristic of the usual forms of congenital adrenal hyperplasia. Clinical evidence of a malignant tumour, such as the palpable abdominal mass and nodular infiltration of the lungs, was substantiated by the failure of high doses of dexamethazone to suppress the abnormally high urinary 17-ketosteroids.

Though Case 2 was not examined personally, there could be little doubt about his precocious puberty and abdominal mass. The diagnosis of adrenal tumour was established in both cases by histology.

\section{Family History}

Figure 6 shows the pedigree. The parents were second cousins. They were both normal. All together they had had nine children as follows:

1. A boy who died at the age of 14 months with proved myelogenous leukaemia.

2. Case 2.

3. A girl who is alive and well at the age of 23 and has two healthy children.

4. A boy who died at the age of $\mathbf{4 0}$ days with probable pneumonia.

5. Case 1.

6. A healthy 11-year old boy.

7. A boy who died at 20 months; he had hydrocephalus.

8. A healthy 5-year-old boy.

9. A healthy 2-year-old girl.

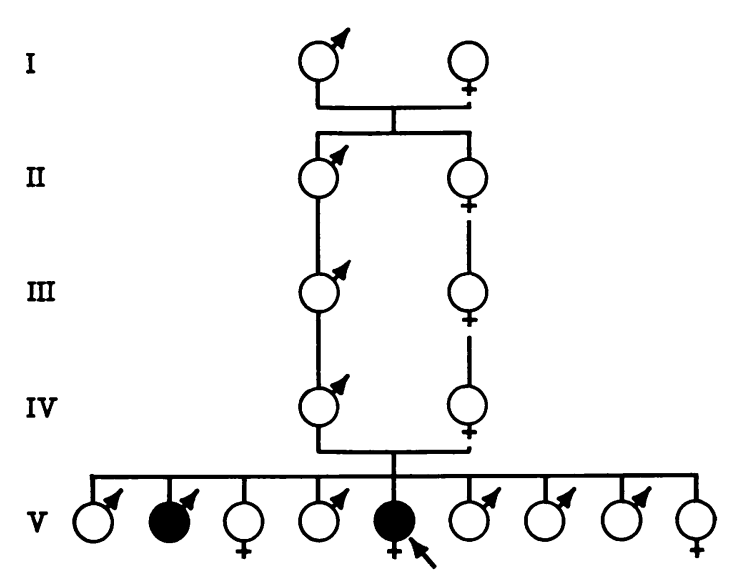

Fig. 6. Pedigree of the family.

\section{Comment}

The familial nature of virilization due to adrenal hyperplasia (adrenogenital syndrome) has long been established (Stanbury, Wyngaarden, and Fredrickson, 1966). The mode of inheritance in all the various types is autosomal recessive (McKusick, 1968). However, neoplasm of the adrenal cortex in close relatives has been described only in two previous reports (Fraumeni and Miller, 1967; Kenny et al, 1968). In 1967, Fraumeni and Miller reported 62 children with tumour of the adrenal cortex. Two of these were sibs and both had carcinoma of the adrenal gland. It was not mentioned if they were virilizing. After a thorough review of 
the literature, they concluded that their family was the first example of documented adrenocortical carcinoma in close relatives. More recently, Kenny et al (1968) have reported adrenal tumours in two first cousins. In one it was virilizing but again the clinical details of the second case were not mentioned.

The present family is the first to show both consanguinity and documented virilizing tumour of the adrenal gland in two sibs. The absence of abnormality in the parents, the mixed sexes of the affected sibs, and the second cousin marriage strongly suggest autosomal recessive inheritance.

The unusual frequency of congenital anomalies and tumours of other organs in the relatives of patients with adrenocortical neoplasms has been stressed in the two previous reports. It may therefore be significant that in the present family one sib had hydrocephalus and another died of myeolgenous leukaemia.

\section{Summary}

A family is described in which 2 sibs, a boy and a girl, had virilizing tumours of the adrenal cortex proved histologically. The parents were second cousins, suggesting an autosomal recessive mode of inheritance.

We wish to thank Dr Ann Forbes and Dr Russell Barakat for helping in the clinical evaluation of the patient and $\mathrm{Dr}$ David L. Rimoin for constructive criticism.

\section{REFBRENCES}

Fraumeni, J. F., Jr. and Miller, R. W. (1967). Adrenocortical neoplasms with hemihypertrophy, brain tumors, and other disorders. Fournal of Pediatrics, 70, 129-138.

Kenny, F. M., Hashida, Y., Askari, H. A., Sieber, W. H., and Fetterman, G. H. (1968). Virilizing tumors of the adrenal cortex. American Fournal of Diseases of Children, 115, 445-458.

McKusick, V. A. (1968). Mendelian Inheritance in Man. Catalogs of Autosomal Dominant, Autosomal Recessive and X-linked Phenotypes. 2nd ed. Johns Hopkins Press, Baltimore.

Stanbury, J. B., Wyngaarden, J. B., and Fredrickson, D. S. (1966). The Metabolic Basis of Inherited Disease, 2nd ed. McGraw-Hill, New York. 